\title{
Queremos ser Glauber ou uma experiência de criação em vídeo
}

\author{
Silvia Biebl
}

O crítico de cinema Paulo Emílio Sales Gomes, em "Cinema, Trajetória do Subdesenvolvimento", menciona a "incapacidade criativa em copiar" do cinema brasileiro ${ }^{1}$. Três palavras dessa formulação, para mim tão rica de sentidos quando tomadas separadamente, tornam-se ainda mais significativas na estranha, mas intuitivamente compreendida formulação de Paulo Emílio. Este projeto surgiu por minha própria incapacidade. Incapacidade criativa. Incapacidade criativa em copiar. Juntar essas três palavras foi a única maneira de conciliar minhas necessidades criativas a uma oportunidade de desenvolver um trabalho de ficção com grande equipe e equipamentos a minha disposição ${ }^{2}$.

Daí o chamado falso documentário. Digo falso documentário porque não sei mesmo o que estou fazendo, porque no fundo gostaria de fugir deste tipo de explicaçāo, gostaria de entrar nessa zona intermediária, onde os limites ficam mais imprecisos e a imprecisão destes limites, mais perceptivos. Talvez seja mais simples dizer: eu não sei por que faço isso, apenas sei que deve ser assim. Porém, é certo que devemos mostrar um suposto domínio do que fazemos aparentemente de forma natural, questionar o que nos leva a dizer alguma coisa e não outra. Por esta razão é que prossigo. Racionalmente, parto do princípio de que há algo instituído que chamamos documentário, algo instituído que chamamos ficção, e de que há certas características pertencentes a esses domínios - mesmo

1 GOMES, Paulo Emílio Salles. Cinema: trajetória no subdesenvolvimento. São Paulo: Paz e Terra, 1996. p. 90.

2 O roteiro aqui apresentado foi gravado em outubro de 2006, como Trabalho de Conclusão de Curso do curso de Comunicação Social - Habilitação em Cinema e Vídeo, da Universidade do Sul de Santa Catarina (UNISUL). 
que de forma não exclusiva. Acredito que a maneira que meu vídeo se constituiu, porém, apresenta possibilidades de criticar tais barreiras, ou, melhor ainda, fazer com que elas percam importância.

Tenho então duas questões principais a serem discutidas. A primeira, em uma divisão esquemática, seria o tema, a respeito do que meu vídeo trata, o que ele quer dizer. O tema deste vídeo (capítulo I) é a incapacidade e a negação que podem envolver qualquer ato criativo ou humano. No nível dos personagens - Marcelo de Campos e Rô -, percebe-se que a criação, transformadora, aqui ausente, só existe quando se parte de uma busca pessoal - mesmo que esteja inevitavelmente ligada a criações prévias. Apesar do uso da figura de Glauber Rocha como inspiração e do caráter metalingüístico do vídeo, não considero este um vídeo sobre Glauber Rocha nem sobre o processo de fazer um filme. Glauber Rocha está presente, sim, como problemática, na relação duvidosa entre o não-fazer e o copiar proposto pelo vídeo.

Os personagens principais, dois extremos de um mesmo problema, mostram que Glauber Rocha é definitivamente um divisor de águas no cinema nacional, mas que a suposição de um mito revela também seu lado negativo - o mito como entrave, evidente na desistência radical e no insistir. É por isso que os dois personagens centrais se encontram em permanente ambigüidade. Rô, o personagem-cineasta mais novo, surge em um fluxo de palavras que insinua um desejo de rompimento e um sentimento de aprisionamento. Desbocado e prepotente, não sabe por que quer copiar Glauber Rocha. Sua necessidade de afirmação também afirma sua dependência a Glauber. Marcelo de Campos, apesar de sua desistência partir de uma escolha pessoal, de algo que falta nele mesmo, também se justifica em Glauber.

A segunda questão a ser discutida é como meu vídeo trata o tema, que recursos utiliza para gerar sentido. Um primeiro recurso, já mencionado, é a utilização de elementos tradicionalmente inseridos em uma estética documental, a narração em voice-over e uso de depoimentos, por exemplo, cuja intenção é indicar uma realidade supostamente anterior ao vídeo (intenção que se reflete também na busca de um tratamento realista da imagem e do som). Como as personagens e as situaçóes que elas implicam são por mim consideradas extremas, absurdas, a única maneira que consegui com que existissem foi de forma literal, material. Na verdade, interessa-me saber o que essas pessoas falariam, se pudessem ser escutadas. A busca por depoimentos, muitas vezes longos, faz parte desse interesse em explorar a fala. Acredito que o recurso da fala, do depoimento no cinema, pode potencializar a imagem. $\mathrm{O}$ cinema não é feito só de ação. Utilizo o documentário, portanto, como enredo para o vídeo.

A divisão em capítulos serve para formar uma unidade temática baseada em opostos - velho/novo, silêncio/verborragia, insistência/desistência, Marcelo de Campos/ Rô. Esta divisão, porém, contribui para a estética fragmentária, não-unitária que compõe o vídeo. Ao mesmo tempo em que ela cria a ilusão de um vídeo inteiro, que uniria este e outros capítulos, também interrompe, provoca hiatos, vazios, que busco durante todo o vídeo. Isso porque algo falta. Este algo é algo que pára por ali, entre os personagens, entre um fazer e um não-fazer, que impede que algo de novo realmente aconteça.

Queremos ser Glauber é um vídeo sobre cinco personagens cujas carreiras são demarcadas pela figura do cineasta Glauber Rocha. Os personagens que supostamente compõem o documentário são: um cineasta cujo projeto é refilmar os filmes de Glauber Rocha exatamente como existem; um cineasta bem-sucedido no passado que 
parou de filmar quando Glauber Rocha começou a fazer sucesso como cineasta; um estudante que vive para reeditar os filmes de Glauber, supostamente levando-os à perfeição; um pesquisador que desiste da vida acadêmica para se dedicar a uma publicação sobre Glauber Rocha, que apenas contém artigos de sua autoria; e uma criança que, futuramente, terá as mesmas idéias de filmes que Glauber, sem saber de sua existência. O Capítulo I - O velho e o Novo apresenta os personagens Marcelo de Campos e Rô, respectivamente, o cineasta que desiste da carreira quando Glauber faz sucesso como cineasta e o cineasta que quer refazer toda a obra de Glauber Rocha.

$O$ roteiro que se segue tem como objetivo provocar discussões a partir de uma rede de dizeres já estabelecida, a saber, Glauber Rocha. Quer questionar não o que se fala, mas como se fala: o peso da discussão se encontraria menos sobre o que se diz a respeito de Glauber, e mais sobre a possibilidade de um espaço a partir do qual falar de Glauber Rocha produziria sentido. Com isso, pretende-se indicar que os dois personagens estão aprisionados por uma rede na qual se constituem e falam, e pela qual seus atos criativos inexistem. É bem literal: os personagens falam sobre Glauber Rocha, só que o espaço a partir do qual eles podem produzir não é o mesmo de onde eles estão falando - as potencialidades dos personagens não são possíveis nesse espaço marcado pela existência de Glauber.

\author{
Queremos ser Glauber \\ Capítulo um: o velho e o novo \\ Um roteiro de \\ zzSilvia Biehl \\ $5^{\circ}$ Tratamento
}

CRÉDITOS

CORTA PARA

01

STILI.

NARRADOR fala em voice-over, enquanto aparecem na tela still dos cinco personagens do documentário sob a foto de Glauber Rocha em seus rostos:

\title{
NARRADOR
}

(VOICE-OVER)

Cinco personagens. Um mesmo sintoma: a incapacidade de superar a genialidade de Glauber Rocha, o maior mito do cinema nacional. Quem são esses cineastas que, para seguirem adiante em suas carreiras, utilizam-se das obras de Glauber para sobreviver a suas próprias renuncias e ultrapassar suas incapacidades? 
CRÉDITOS

CAPÍTULO I: O VELHO E O NOVO

02

EXT/INT - JARDIM DE MARCELO DE CAMPOS/SET DE GRAVAÇÃO - DIA

O narrador prossegue em voice-over, enquanto a tela é recortada em duas. De um lado, MARCELO DE CAMPOS, 73, fala enquanto caminha em direção à sua estufa. Do outro lado, RÔ, 27, está assistindo à gravação de uma cena. Ele diz corta e as pessoas se movem ao redor do set. Rô chama os atores e dá indicações.

\section{NARRADOR \\ (VOICE-OVER)}

Marcelo de Campos e Rô. O

primeiro, cineasta de meteórica carreira na extinta Atlântida. Em 1964, ano em que Glauber Rocha se consagra com "Deus e o Diabo na Terra do Sol", Marcelo abandona a profissão. Coincidência? Acaso? Rô, formado em cinema, produz seu terceiro filme, "Deus e o Diabo na Terra do Sol", depois da gravação de "Pátio" e "Câncer". Não recebe qualquer apoio institucional para a realização de seus filmes.

03

INT - SET DE GRAVAÇÃO - DIA

Rô concede entrevista, sentado em uma cadeira.

\section{RÔ}

Sempre se diz que os cineastas tão refilmando incessantemente os mesmos filmes. Aí, você vê, eu tô refilmando a obra de Glauber, essa belezura aí, e não posso! Sei lá! Quem disse que eu não posso?

04

EXT - JARDIM DE MARCELO CAMPOS - DIA

Marcelo de Campos está em seu jardim regando plantas.

\section{MARCELO DE CAMPOS}

(OFF)

Você vê um filme daqueles... Todo rebuscamento, toda qualidade, 
toda... O que é que nós estamos fazen-

do? Acabou. Não tem mais o que fazer.

05

EXT -JARDIM DE MARCELO CAMPOS - DIA

Sentado em seu jardim, Marcelo de Campos espera em silêncio.

06

EXT - SET DE GRAVAÇÃO - DIA

Rô assiste ao videoassist, e conversa sobre a iluminação com o diretor de fotografia, revisando o roteiro. Dá indicações para o eletricista. Rô fala em off.

RÔ

(OFF)

É lógico que eu não sei explicar. (risos) Isso você corta. A verdade é que eu tô fazendo muito melhor do que Glauber fez, tá me entendendo? Tô fazendo muito melhor, mas claro que isso aí ninguém fala, o cara tá preocupado em dizer que eu sou um falsário. Glauber taria feliz da vida em ver meu projeto.

Rô aparece em entrevista sentado em uma cadeira

RÔ

Tá, a diferença... A diferença é que a gente não tá mais na mesma ép. oca, ok... Claro (vozes interrompendo ao fundo), sim, claro, mas é que você pode tirar do contexto e ver o que aquilo tem... Põe o bigodinho na Monalisa, ela vira outra coisa. Pode ver, tem livro sobre isso! Eu preciso saber como esses filmes são o que são hoje. (Pausa, olha para a câmera) Tá me entendendo?

07

INT - SALA DE MONTAGEM - NOITE

Marcelo de Campos está sentado na sala de montagem, em frente à moviola.

MARCELO DE CAMPOS

(OFF) 
É possível dizer, sim, que se tem o domínio técnico, mas, no campo criativo, você precisa de mais. É o que chamam de inspiração. $\mathrm{E}$ a minha acabou há muito tempo. Eu queria me dedicar às outras coisas. Eu não desisti de fazer mais filmes, eu apenas não os fiz mais.

Marcelo concede entrevista.

\section{MARCELO DE CAMPOS}

Eu desisti dos meus filmes porque eles desistiram de mim. Descobri algo em mim que não se fazia com o dinheiro. A paixão pela minha profissão foi diminuindo a tal ponto que tornouse nula. $\mathrm{O}$ que significa reiventar? $\mathrm{Na}$ época, nós refilmávamos muito, mas, quando não tinha mais nada naquilo, a gente chamava de "cadáver" porque, muitas vezes, era uma cópia mal feita. E o público sente a cópia mal feita, porque falta o sentimento.

08

INT - SET DE FILMAGEM - DIA

CORISCO, 25 anos, ensaia texto de "Deus e o Diabo..." de frente para a câmera. Depois relaxa a postura e ri.

\section{CORISCO}

Eu, José, com a espada de Abraão serei coberto. Eu, José, com o leite da virgem Maria serei borrifado. Eu José, com o sangue de Cristo serei batizado. Eu, José, na arca de Noé serei guardado. Eu, José, na chave de São Pedro serei fechado, onde não me possam ver $\mathrm{e}$ ferir, nem me matar nem o sangue de meu corpo tirar.

09

INT - SET DE FILMAGEM - DIA

Produtor concede entrevista. 
PRODUTOR

Bem, é difícil, não é mesmo?

Quando a gente se conheceu, a gente começou a fazer cinema... A faculdade, né, e, ahm, a obra do Glauber sempre teve lá, sempre em algum exercício. A gente até sacaneava...(risos) Daí a gente se formou, e um dia o cara me liga, poxa, eu quero refilmar o "Deus e 0 Diabo", como eu faço? Daí, eu, como assim, como? Daí ele, é! Como?, com que produção, vamos fazer isso aí! (risos) Imagina, fotograma por fotograma, cena por cena! A gente contorna... É uma pena porque ele, a gente nunca vai conseguir dinheiro pra fazer isso e a gente tem que cuidar onde vai passar, mas no fim a gente topa, né? Eu topo a onda dele, eu gosto do que ele faz.

10

EXT - JARDIM DE MARCELO CAMPOS - DIA

Marcelo de Campos concede entrevista sentado em uma cadeira em seu jardim.

\section{MARCELO DE CAMPOS}

Não, não, nunca conheci o Glauber. Teve uma vez que um amigo em comum quis me apresentar. Fiquei esperando cinco horas o cidadão aparecer em uma festa em homenagem a ele e fui saber que ele chegou cinco minutos depois que eu saí. Eu imagino que ele nem imaginava quem eu era, apesar de eu ser muito conhecido no Rio. Mas eu fazia outro tipo de cinema. Justamente aquele que, não, sei, pra mim não fazia o menor sentido conhecer um homem daquele. Não acho que era vergonha. Bem, eu tive vergonha sim, não sei, eu parei, eu não podia continuar mais. Olhando hoje eu acho que eu fiz uma coisa boa pro cinema nacional (risos). Mas na época eu simplesmente me retirei, 
aquilo não fazia sentido. Eu nem sabia o que era política, aquelas coisas todas, mas eu vi que eu tava fazendo alguma coisa errada.

Marcelo de campos fica em silencio, olhando para a câmera. Fica um tempo assim, até que se levanta.

11

INT - SALA DE PROFESSOR -

PESQUISADORA, 40, concede entrevista sobre os personagens.

\section{PESQUISADORA}

É por isso que eu estava te falando. Pra mim eles representam duas coisas. Uma é a da importância do mito na identidade nacional, e mais especificamente de um cinema nacional. Glauber Rocha é, inegavelmente, a marca de nossa nacionalidade, ele faz ser o que nós somos em cinema. A outra proposta é a de que Glauber, e isso vai de acordo com o que eu estava falando, a proposta é que Glauber é a nossa imagem, porque eu acredito que só ele possibilitaria a existência dessas personagens tão impressionantes. Se eles existem hoje, e, dizendo assim é meio óbvio, mas esses personagens só existem porque Glauber existe. Pra mim, esses homens não buscam Glauber, são parte de seu cinema.

12

EXT - JARDIM DE MARCELO CAMPOS - DIA

Marcelo de Campos está em seu jardim regando plantas .

13

INT - SET DE GRAVAÇAO - DIA

Rô ensaia os atores na refilmagem de "Deus e o Diabo na Terra do Sol". Está dirigindo o ator até que pára, e fica por alguns instantes calado e parado, como se longe. Depois retoma a indicação e dá sinal pra equipe que está na hora de filmar. A câmera, que está mostrando a equipe, se vira para enquadrar apenas Rô, e vemos, sozinhos no 
quadro, Rô observando a cena e Marcelo de Campos, parado, encostado em uma parede ao fundo. $\mathrm{O}$ ator começa a encenar. Rô fala em off, seguido, alguns segundos depois, de Marcelo de Campos.

\author{
RÔ \\ (OFF) \\ E daí pro que Glauber tá \\ achando disso tudo, tá me entendendo? \\ O Glauber não tem que achar nada não. \\ MARCELO DE CAMPOS \\ (OFF) \\ É preciso um bom motivo e \\ muita coragem para pedir emprestado \\ algo de alguém e inutilizar a coisa. Eu \\ me vi em uma situação em que só copi- \\ aria Glauber, e então vi que tinha algo \\ de errado comigo. Às vezes, é melhor \\ ficar calado.
}

\title{
CRÉDITOS
}

CAPÍTULO II: O MEIO

FIM

Queremos ser Glauber é um projeto pequeno, que foi realizado na tentativa de conciliar limitações técnicas e pessoais. Pensando o cinema libertador como algo muito mais sutil do que a utilização de fórmulas libertárias, gostaria que este vídeo fosse uma provocação que servisse para pensarmos sobre o cinema brasileiro hoje. Gostaria que essa provocação também servisse para questionar a minha prática como realizadora. Apesar de algumas pessoas gostarem de ver esse vídeo como representação de alguns "tipos" em cinema, não pensei em nenhuma pessoa ou grupo de pessoas alvo de uma crítica na hora da criação desses personagens. Eles nasceram, acredito, como metáforas para dilemas próprios que, gostaria de acreditar, fariam eco a questões mais gerais do que figuras de nosso cinema.

Marcelo de Campos, o personagem com quem mais me identifico, é para mim a constatação às vezes triste de que é perfeitamente possível viver sem o cinema. Sua desistência, que pode ser interpretada como resignação, tem para mim um sentimento muito profundo de constatação das incapacidades. É tanto um ato de covardia - porque, ao constatar que não se pode ser grande, desiste-se - ao mesmo tempo em que é um ato de coragem - saber admitir a própria incapacidade diante de algo maior. Rô, por outro lado, é o lado da insistência, da tentativa de ir em frente mesmo quando tudo parece indicar o fracasso, ao custo de ser até mesmo ridículo. Rô é patético ao mesmo tempo em que consegue espelhar algo que já pode ter passado dentro da cabeça de qualquer estudante de cinema: tentar não é sempre um ato de sucesso, mas é a única 
forma de tentar.

Se a análise da fortuna crítica de Glauber Rocha por Felipe Soares ${ }^{3}$ revela um embate que redunda na renúncia da alegria pelo totem, pode-se pensar o espaço de "liberdade" e criatividade desses personagens (e de Glauber) dessa forma, como o vazio (do vídeo) a partir do qual é possível fazer relações com outros dizeres. Assim, trata-se não de uma exaltação do Glauber por meio de mil adjetivos, mas do uso deliberado de seu cinema (ou de qualquer outro, apesar de aqui mencionar Glauber em especial) para tentarmos passar do totem à alegria.

3 "A crítica parece ter caído em uma encruzilhada: ou não decifra Glauber e se deixa marcar, por ele mesmo, como imbecil, ou o decifra e the reitera o caráter totêmico. Seja como for, participa, em geral, do mesmo sistema de valores observável em declarações de Rocha que perseguem a revolução, ou seja, é feita em obediência à personagem que ajuda a construir" (SOARES, p,05) In: SOARES, Felipe. Depois de Glauber: a alegria contra o totem. Revista AV. São Leopoldo - RS, v.2, n.3, 2004. 